\title{
Produção de novilhos superprecoces em pastagem de aveia e azevém submetida a diferentes alturas de manejo ${ }^{1}$
}

\author{
Angelo Antonio Queirolo Aguinaga ${ }^{2}$, Paulo César de Faccio Carvalho ${ }^{3}$, Ibanor Anghinoni ${ }^{4}$, \\ Davi Teixeira dos Santos ${ }^{5}$, Fabiana Kellermann de Freitas ${ }^{5}$, Marilia Terra Lopes ${ }^{6}$
}

1 Parte da dissertação de Mestrado do primeiro autor.

${ }^{2}$ Mestrando do PPG - Zootecnia/UFRGS. Bolsista CAPES.

${ }^{3}$ Departamento de Plantas Forrageiras e Agrometeorologia/UFRGS - Av. Bento Gonçalves, 7712, CEP: 91501-970, Porto Alegre, RS, Brasil.

${ }^{4}$ Departamento de Solos/UFRGS.

${ }^{5}$ Doutorando do PPG - Zootecnia/UFRGS, bolsista CNPq.

${ }^{6}$ Mestranda do PPG - Zootecnia/UFRGS.

RESUMO - Foram avaliadas a produção e as características de carcaças de novilhos jovens mantidos em pastagem cultivada de aveia preta (Avena strigosa Schreb) e azevém (Lolium multiflorum Lam) manejada em diferentes alturas. Os tratamentos impostos foram quatro diferentes alturas de manejo da pastagem $(10,20,30$ e $40 \mathrm{~cm})$, obtidas por meio da aplicação de diferentes cargas animais. O delineamento foi o de blocos casualizados, com três repetições. Utilizaram-se animais jovens de aproximadamente dez meses de idade, machos castrados sem padrão racial definido, com peso médio inicial de $210 \mathrm{~kg}$. O aumento no ganho médio diário (GMD) foi condicionado pelo incremento na qualidade e/ou na quantidade de forragem disponível, visto que as ofertas de forragem para os tratamentos de 10,20,30 e $40 \mathrm{~cm}$ de altura foram de $6,10,23$ e $51 \mathrm{~kg}$ de $\mathrm{MS} / 100 \mathrm{~kg}$ de $\mathrm{PV} / \mathrm{dia}$, respectivamente. Portanto, o modelo de resposta do GMD em relação às alturas de pastejo resultou em valores de 0,73 e $1,14 \mathrm{~kg} /$ animal/dia nos tratamentos de menor e maior GMD, respectivamente, que foram de 10 e $30 \mathrm{~cm}$ de altura. Como a variação no GMD foi baixa, o maior ganho por área observado no tratamento $10 \mathrm{~cm}$ pode ser atribuído à maior carga animal, ambas com respostas lineares decrescendo com o aumento da altura de pastejo. O peso vivo dos animais antes do abate e o peso de carcaça quente elevaram com o aumento da altura da pastagem, reduzindo apenas no tratamento $40 \mathrm{~cm}$ com a redução da qualidade da pastagem. Não houve diferença entre os tratamentos para o rendimento de carcaça, pois todos os valores mantiveram-se em torno de $51 \%$. O escore de condição corporal e o grau de acabamento apresentaram tendência muito similar à evolução do ganho médio diário dos animais.

Palavras-chave: altura da pastagem, carga animal, ganho médio diário, ganho por área, oferta de forragem

\section{Production of beef steers grazing oat plus annual ryegrass pasture managed at different heights}

\begin{abstract}
The objective of this trial was to evaluate production and carcass characteristics of young steers grazing a mixture of black oat and Italian ryegrass pasture. Treatments were four different pasture heights $(10,20,30$, and $40 \mathrm{~cm})$ that were obtained with different stocking rates. Fifty-five beef steers averaging $210 \mathrm{~kg}$ of body weight and 10 months of age at the beginning of the trial were used in a randomized complete block design with three replicates. The observed increase in the average daily weight gain (ADG) was associated with the quality and/or amount of available forage because herbage allowance increased from 6 to $51 \mathrm{~kg} \mathrm{DM} / 100 \mathrm{~kg} \mathrm{BW}$ when pasture height was enhanced from 10 to $40 \mathrm{~cm}$. Therefore, the ADG was 0.73 and $1.14 \mathrm{~kg} / \mathrm{animal} / \mathrm{day}$ for the treatments with the lowest and highest ADG, which corresponds to 10 and $30 \mathrm{~cm}$ pasture height. Considering the low ADG, the greatest gain/area observed on the $10 \mathrm{~cm}$ treatment may be explained by a greater stocking rate; both ADG and stocking rate decreased linearly by increasing pasture height. Body weight and hot carcass weight increased until $30 \mathrm{~cm}$ of pasture height but decreased at $40 \mathrm{~cm}$ because of poorer pasture quality. There was no difference on carcass yield, which averaged $51 \%$ among treatments. The body condition score and carcass fat thickness followed the ADG in this trial.
\end{abstract}

Key Words: average daily gain, forage allowance, gain per area, pasture height, stocking rate

\section{Introdução}

A produção agropecuária na Região Sul do Brasil apresenta situações contrastantes. Quanto à agricultura, durante os últimos 20 anos, a produtividade tem aumentado a com o adequado emprego de tecnologias modernas. Todavia, em virtude do baixo emprego de tecnologias economicamente viáveis, a produtividade pecuária tem apresentado aumento inexpressivo em comparação à agricultura no mesmo período. 
Para a Região Sul do Brasil, o período de outonoinverno constitui-se um ciclo de baixa disponibilidade de forragem das pastagens naturais, como demonstrado por Moojen \& Maraschin (2002). Portanto, as pastagens cultivadas de estação fria são alternativas para reduzir as perdas no período desfavorável para o campo nativo, permitindo aos animais ganhar peso também nesse período.

O Rio Grande do Sul possui aproximadamente 5,0 milhões de hectares cultivados anualmente com soja (Glycine max) e milho (Zea mays), dos quais apenas 18\% são utilizados para o plantio de trigo (Triticum aestivum), aveia, branca (Avena sativa), cevada (Hordeum vulgare) e centeio (Secale cereale), enquanto o restante, em torno de 4,0 milhões de hectares, permanece praticamente sem renda durante o inverno (Cassol, 2003), apenas como cobertura de solo ou pousio, representando excelente potencial para o uso com animais no período crítico. Mesmo assim, o Rio Grande do Sul é o estado brasileiro com maior número de animais terminados em pastagem cultivada de inverno: cerca de 420 mil cabeças em 2003, cinco vezes mais que Paraná e Santa Catarina, segundo e terceiro estados produtores, respectivamente (Anualpec, 2004). A maior utilização de pastagem cultivada no inverno no RS, em relação aos demais, deve-se principalmente às grandes áreas de integração lavoura-pecuária das regiões do Planalto Médio, Missões e Alto Uruguai grandes produtoras de grãos no verão.

O plantio de coberturas de solo ou de culturas de alto risco econômico, como os cereais de inverno, leva o agricultor a buscar alternativas econômicas durante este período. Portanto, o uso de pastagens hibernais com elevado valor nutritivo e alto potencial produtivo torna viável a terminação de bovinos durante a entressafra e surge como alternativa para o aumento de rentabilidade das empresas rurais. Como o produto final é a carne, todo o esforço de aumento em produtividade deve resultar em carne de qualidade desejável pelo consumidor. Com isso, a intensificação da pecuária de corte, via pastagens de qualidade, deve oferecer um produto que satisfaça às exigências tanto das plantas frigoríficas, com peso e acabamento adequados, quanto ao consumidor varejista, que exige, cada vez mais, carne macia e de qualidade.

Este experimento foi realizado com o objetivo de avaliar a produção e as características de carcaças de novilhos jovens com 14 meses de idade mantidos em pastagem cultivada de aveia preta (Avena strigosa Schreb) e azevém (Lolium multiflorum Lam) manejada com diferentes alturas, em um sistema de integração lavoura-pecuária. Esse sistema visa à terminação desses animais em um único ciclo de inverno, permitindo, portanto, que áreas destinadas à agricultura não sejam ocupadas no verão, favorecendo a adoção dessa técnica por parte dos produtores. Além de viabilizar o sistema de produção proposto, o novilho superprecoce atende também a uma demanda concentrada em nichos de mercado com a produção de carne de qualidade, proveniente de animais jovens e de raças britânicas, que apresentam peso de carcaça em torno de $170 \mathrm{~kg}$ e grau de acabamento de aproximadamente $3,0 \mathrm{~mm}$ de gordura, satisfazendo às necessidades dos mercados mais exigentes.

\section{Material e Métodos}

O experimento foi conduzido na Fazenda Espinilho, no município de São Miguel das Missões, região fisiográfica do Planalto Médio do Rio Grande do Sul.

A área experimental utilizada vem sendo trabalhada há 11 anos no sistema de semeadura direta; no inverno, é cultivada com aveia e no verão, com soja. Em 2000, a área experimental recebeu, pela primeira vez, o pastejo de animais. A partir de então, a exploração da área no inverno passou a ser com animais.

O solo é classificado como Latossolo Vermelho Distroférrico típico (Embrapa, 1999), desenvolvido a partir de rochas eruptivas básicas, sendo profundo, bem drenado, com coloração vermelho-escura e textura muito argilosa $(>600 \mathrm{~g} / \mathrm{kg})$. O relevo configura-se ondulado a suavemente ondulado.

Os quatro tratamentos consistiram de diferentes alturas de manejo da pastagem de aveia+azevém, sendo as alturas de 10, 20, 30 e $40 \mathrm{~cm}$ as alturas médias pretendidas. Os tratamentos foram dispostos em delineamento experimental de blocos ao acaso, com três repetições, totalizando 12 unidades experimentais, em uma área de aproximadamente 21,5 ha.

Foram utilizados 55 animais jovens, de aproximadamente dez meses de idade, machos castrados sem padrão racial definido, com peso médio inicial de $210 \mathrm{~kg}$ e peso médio de abate de $320 \mathrm{~kg}$, provenientes da própria Fazenda Espinilho.

No dia anterior ao início do pastejo, os animais foram pesados após jejum prévio de 12 horas, vermifugados com aplicação de Ivermectina na dosagem de 5,0 ml/animal e identificados com brinco.

O pastejo foi realizado pelo método contínuo com taxa de lotação variável, composto por animais-teste e reguladores. Os animais reguladores foram colocados e retirados da pastagem conforme a necessidade de ajuste da altura, usando-se a técnica "put-and-take" descrita por Mott \& Lucas (1952).

No dia 19/05/03, foi realizada a semeadura das espécies de inverno, aveia preta (100 kg sementes/ha) + azevém 
(25 kg sementes/ha), procedendo-se à adubação com base nos resultados da análise do solo (400 kg de superfosfato simples/ha). A aplicação do nitrogênio em cobertura ocorreu em 04/07/03, na dose de $90 \mathrm{~kg}$ de N/ha na forma de uréia.

Os animais foram colocados na pastagem no dia 21/07/03, quando o perfil da pastagem atingiu $25 \mathrm{~cm}$ de média (em torno de $2.000 \mathrm{~kg} / \mathrm{ha}$ de MS), e se estendeu até 07/11/03, quando os animais foram retirados e abatidos.

As alturas da pastagem foram medidas com um bastão graduado "sward stick", cujo marcador corre por uma "régua" até tocar no topo da superfície da pastagem, no toque da primeira folha, procedendo-se então à leitura da altura, em cm (Barthram, 1985). O controle da altura da pastagem foi feito em intervalos de 15 dias aproximadamente, totalizando sete avaliações. A leitura foi feita em 100 pontos dentro de cada unidade experimental, em caminhamento aleatório, a fim de se definir a altura média da pastagem.

O valor médio das medições do "sward stick" de cada potreiro foi utilizado como variável independente em equações de regressão linear que relacionaram as medições de altura ao valor de massa de forragem real (MF), que foi avaliada a cada 30 dias, aproximadamente, de forma aleatória, em quatro pontos por parcela, utilizando-se um quadro de $0,25 \mathrm{~m}^{2}$.

Para determinação da taxa de acúmulo diário de MS da pastagem (TAD), realizada a cada 30 dias aproximadamente, foram utilizadas três gaiolas de exclusão de pastejo por unidade experimental, empregando-se a técnica do triplo emparelhamento (Moraes et al., 1990). A oferta de forragem (OF) por repetição foi calculada dividindo-se a MF por 30 dias somada com a TAD. O valor obtido foi multiplicado por 100 e dividido pela carga animal.

O valor nutritivo da forragem foi estimado por duas amostragens realizadas em datas distintas ao longo do período experimental (uma amostragem por potreiro a cada avaliação). $\mathrm{O}$ material foi seco em estufa de circulação forçada a $65^{\circ} \mathrm{C}$ até peso constante, sendo triturado em moinho tipo "Willey" com peneira de $1 \mathrm{~mm}$ e armazenado em sacos plásticos para posterior análise da composição de PB (Tedesco, 1982) e da digestibilidade in vitro da matéria orgânica(DIVMO) (Alexander, 1969).

Para avaliar o desempenho, foram realizadas três pesagens em jejum prévio dos animais para que se pudesse acompanhar o ganho de peso médio diário (GMD) durante o período, por meio da diferença entre os pesos final e inicial dos animais-teste, dividido pelo número de dias do período.

A carga animal média (CA) do período de pastejo expressa em $\mathrm{kg}$ de $\mathrm{PV} / \mathrm{ha} /$ dia foi calculada, para cada unidade experimental, pela adição do peso médio dos animais-teste, com o peso médio de cada animal regulador, multiplicado pelo número de dias que permaneceu na pastagem, dividido pelo número total de dias de pastejo.

O ganho de peso total por hectare (GPA) foi obtido pela multiplicação da taxa de lotação média ( $\mathrm{n}^{\mathrm{o}}$ de animais/dia) pelo GMD dos animais-teste.

O abate foi realizado no dia 11/11/03, no Frigorífico FRIGONAL, localizado na cidade de Monte Negro-RS. Os resultados apresentados referem-se ao valor médio obtido do abate de nove animais-teste de cada tratamento, ou seja, foram realizadas avaliações em um total de 36 animais. Primeiramente, os animais foram avaliados quanto à condição corporal, atribuindo-se escore de 1 a 5 , em que 5 refere-se ao animal com melhor acabamento, e logo após, foram submetidos a jejum de 12 horas para pesagem.

Após o abate, procedeu-se ao manuseio das carcaças seguindo o fluxo normal da linha de abate do frigorífico, onde foram identificadas, lavadas, pesadas para obtenção do peso de carcaça quente e, em seguida, foram resfriadas a $-2^{\circ} \mathrm{C}$ por 24 horas. Após esse período, as carcaças foram novamente pesadas para determinação dos pesos de carcaça fria, de dianteiro, de traseiro e de costilhar, com o objetivo de determinar o peso dos cortes comerciais. Também foram coletados e analisados os dados de conformação e o grau de acabamento das carcaças, fornecidos pelos técnicos do próprio frigorífico, estimados pelo método de avaliação visual. Os dados foram submetidos à analise de regressão simples pelo seguinte modelo:

$$
\mathrm{Y}_{\mathrm{ij}}=\mu+\mathrm{b} 1 \mathrm{~A}_{\mathrm{i}}+\mathrm{b} 2 \mathrm{~A}_{\mathrm{i}} 2+\operatorname{erro}\left({ }_{\mathrm{i}, j}\right)
$$

em que: $\mathrm{A}=$ alturas de manejo da pastagem $(\mathrm{i}=1,2,3,4)$; b1 = coeficientes lineares de regressão da variável Y em função da altura da pastagem; $b 2$ = coeficientes quadráticos de regressão da variável $Y$ em função da altura da pastagem.

As análises foram feitas pelos procedimentos GLM (General Linear Models) e REG do programa estatístico SAS versão 6.08 (SAS, 1989).

\section{Resultados e Discussão}

Considerando que os animais utilizados apresentavam potencial genético semelhante, o aumento no desempenho animal (GMD), visualizado na Figura 1, foi condicionado pelo incremento na quantidade de forragem disponível, visto que as ofertas de lâminas foliares para os tratamentos de 10, 20,30 e $40 \mathrm{~cm}$ de altura foram de 1,3;1,9;3,9; e 7,7 kg de MS/100 kg PV/dia, respectivamente (Figura 3), demonstrando a importância dos tratamentos na definição do desempenho animal, expresso pelo ganho médio diário. A estrutura do dossel forrageiro é definida como a distribuição e o arranjo das partes das plantas sobre o solo dentro 
de sua comunidade, ou como a quantidade e organização de partes das plantas sobre o solo (Laca \& Lemaire, 2000). Nesse contexto, tanto os parâmetros verticais (altura) como os horizontais da estrutura do dossel são relevantes para a seleção da dieta pelos herbívoros (Carvalho et al., 2001), uma vez que a estrutura do dossel afeta diretamente o consumo de forragem, principal determinante do desempenho animal (Hodgson, 1990; Carnevalli \& Da Silva, 2000; Sarmento, 2003).

O modelo de resposta do GMD às alturas de pastejo resultou em valores de 0,73 e 1,14 kg/animal/dia nos tratamentos de maior $(10 \mathrm{~cm})$ e menor $(30 \mathrm{~cm}) \mathrm{GMD}$, respectivamente. Ganhos semelhantes foram obtidos por Lustosa (1998), que relatou valor de $1,18 \mathrm{~kg} /$ animal/dia, inclusive sob o mesmo tipo de pastagem e com oferta de forragem de $15 \%$ do PV. Moraes (1991) encontrou a maior produtividade animal em pastagem manejada em OF de $10,2 \%$ do $\mathrm{PV}$, valor semelhante ao encontrado neste estudo para pastagem manejada com aproximadamente $25 \mathrm{~cm}$ de altura (10\% do PV) (Figura 3).

Em experimento realizado por Quadros \& Maraschin (1987), com bezerros desmamados em mistura de azevém + trevo vesiculoso (Trifolium visiculosum) e aveia preta + azevém + trevo vesiculoso, os GMD observados foram de 0,883 e $0,705 \mathrm{~kg} /$ animal $/$ dia, respectivamente, considerados baixos, atribuídos ao baixo mérito genético dos animais utilizados no estudo.

Hodgson (1990), no entanto, observou, em pastagem de azevém perene, que o melhor desempenho animal para

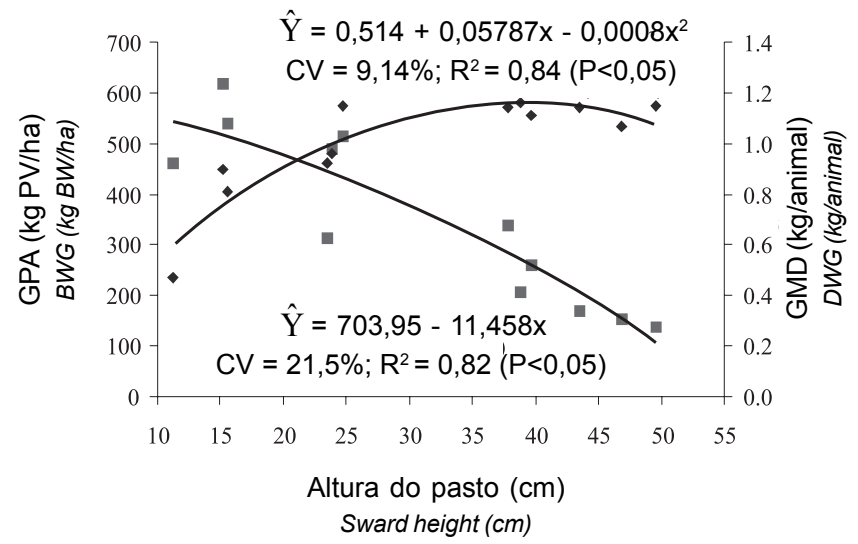

Figura 1 - Ganho médio diário (GMD) (kg PV/animal/dia) e ganho de peso vivo por área (GPA) (kg PV/ha) em pastagem de aveia e azevém manejada com diferentes alturas. A média de cada tratamento é composta por 12 valores (animais-teste). Fazenda Espinilho, São Miguel das Missões, 2003

Figure 1 - Average daily weight gain (DWG) (kg/animal) and body weight gain (BWG) (kg/ha) of young steers grazing oat plus ryegrass pasture managed with different wieghts. Espinilho Farm, São Miguel of Missões, 2003.

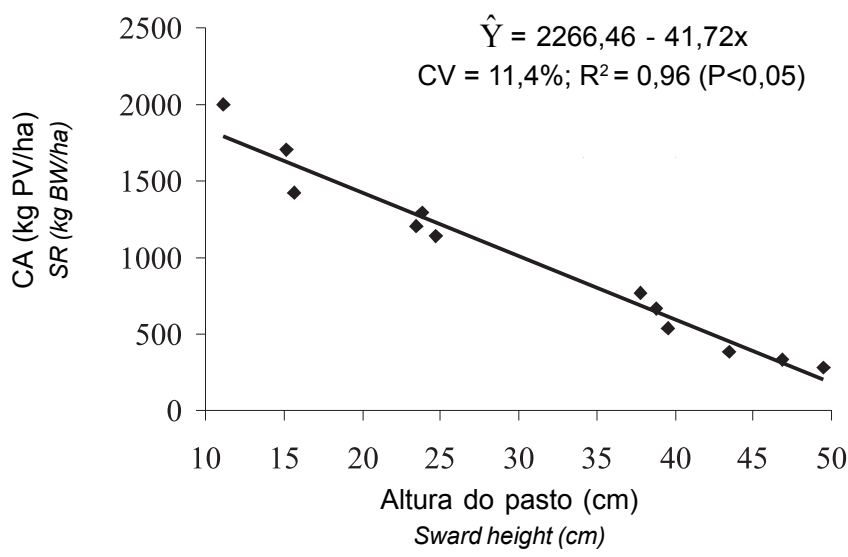

Figura 2 - Carga animal média (CA) (kg PV/ha) em uma pastagem de aveia e azevém manejada em diferentes alturas. Fazenda Espinilho, São Miguel das Missões, 2003

Figure 2 - Mean stocking rate (SR) ( $k g$ BW/ha) of young steers grazing oat plus ryegrass pasture managed with different heights. Espinilho Farm, São Miguel of Missões, 2003.
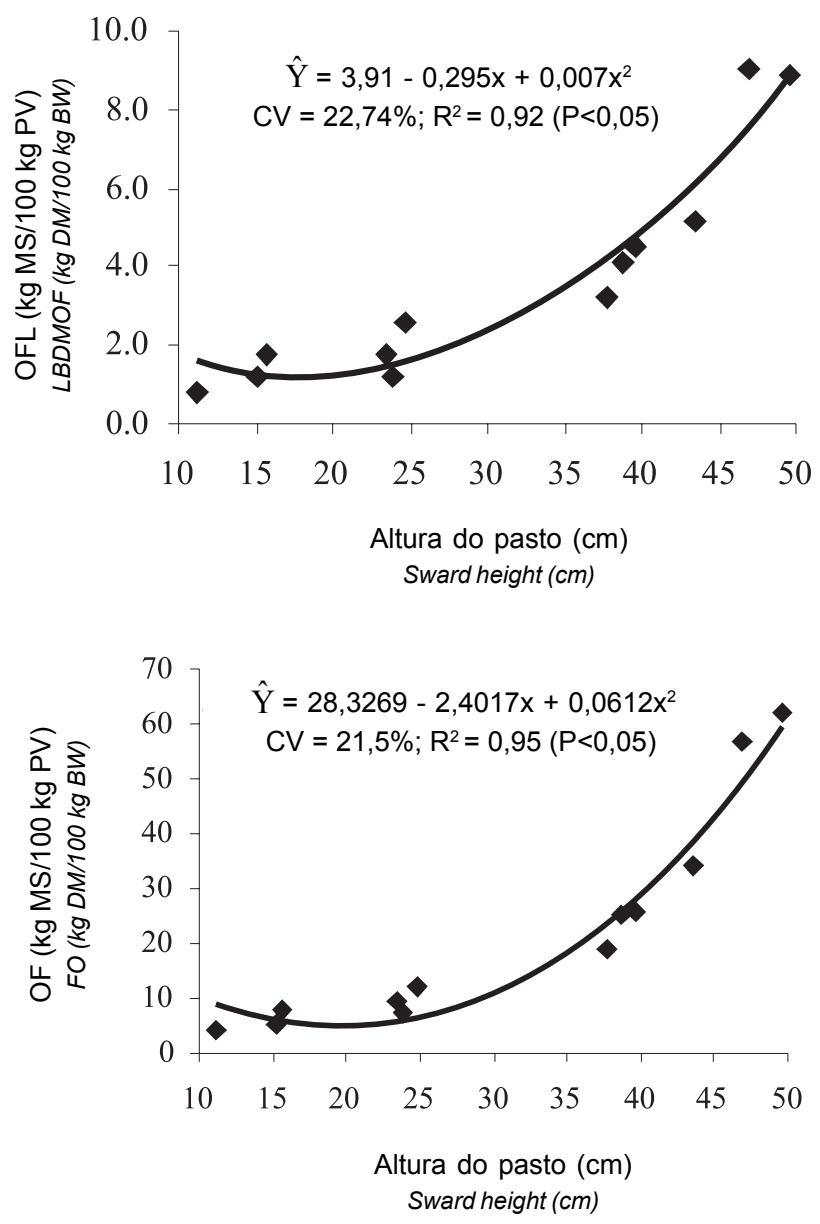

Figura 3 - Oferta de lâmina foliar (OFL) e oferta de forragem total (OF), em kg MS/100 kg PV, de uma pastagem de aveia e azevém manejada em diferentes alturas. Fazenda Espinilho, São Miguel das Missões, 2003.

Figure 3 - Leafblade dry matter on offer (LBDMOF) and total forage on offer (FO), in $\mathrm{kg} D M / 100 \mathrm{~kg} B W$, of oat plus ryegrass pasture managed with different heights. Espinilho Farm, São Miguel of Missões, 2003 
bovinos em terminação ocorre em alturas de $9-10 \mathrm{~cm}$ e OF de 10-12 kg de MS/100 kg de PV. Valores semelhantes ao deste estudo foram relatados para os cultivares tifton-85, florakirk e coastcross de Cynodon (Carnevalli et al., $2001 \mathrm{a}, \mathrm{b}$; Carnevalli \& Da Silva, 2000) com o maior desempenho animal medido em pastagens de 15 a $20 \mathrm{~cm}$ de altura.

A estabilização do GMD na maior altura $(40 \mathrm{~cm})$ provavelmente foi conseqüência de alterações na estrutura (altura de plantas e dispersão de folhas) e/ou na qualidade da pastagem (Figura 4), que podem ocasionar diminuição no consumo, pela redução da profundidade do bocado, e aumento no tempo de pastejo (Carvalho et al., 1999). Evidências apresentadas por Allden \& Whittaker (1970) e Hodgson \& Jamieson (1981) indicam que o aumento na altura de afilhos poderia influenciar o consumo por animais em pastejo e permitir bons níveis de consumo de forragem por animal, até certo ponto, no qual perfis de pastagens com elevado conteúdo de pseudocolmos e material morto parecem inibir o pastejo e limitar a profundidade de pastejo (Barthram, 1981).

A eficiência na utilização da forragem produzida em sistemas de produção animal em pastagens pode ser definida como a proporção da produção de forragem removida pelos animais antes do processo de senescência (Lemaire \& Chapman, 1996). Dessa forma, a utilização é determinante da produtividade de sistemas pastoris e pode ser ajustada por meio da intensidade de desfolhação. Pontes et al. (2004) observaram, para uma pastagem de azevém anual pastejada por cordeiros na melhor altura de manejo $(12,7 \mathrm{~cm})$, necessidade de $26,3 \mathrm{~kg}$ MS para produzir $1,0 \mathrm{~kg}$ de $\mathrm{PV}$, valor superior ao encontrado neste estudo, que, para altura de pastejo de $14 \mathrm{~cm}$, necessita-se $17,1 \mathrm{~kg}$ de MS para produzir 1,0 kg de PV. Assmann et al. (2004), trabalhando com novilhas, obtiveram eficiência de utilização de 7,91 kg MS de aveia + azevém + trevo-branco/kg de $\mathrm{PV}$, o que demonstra o alto potencial das pastagens hibernais em converter produção vegetal em produto animal de qualidade.

Também na Figura 1 são demonstrados os valores de ganho de peso vivo por área (GPA). Observa-se que a produção de $\mathrm{PV} /$ ha apresentou resposta linear e negativa, ou seja, à medida que se aumentou a altura de manejo da pastagem, o GPA reduziu. Como a variação no GMD foi baixa, o maior GPA observado no tratamento $10 \mathrm{~cm}$ pode ser atribuído à aplicação de maior CA (Figura 2).

O GPA e a CA apresentaram respostas lineares (Figuras 1 e 2) e decresceram com o aumento da altura da pastagem e, de acordo com a equação de regressão, cada $\mathrm{cm}$ de aumento na altura da pastagem correspondeu à redução de $42 \mathrm{~kg}$ de PV ha/dia na carga animal (Figura 2). Embora o tratamento $10 \mathrm{~cm}$ de altura tenha possibilitado produção de $5 \mathrm{~kg}$ de $\mathrm{PV} / \mathrm{ha} / \mathrm{dia}$, os animais no final do ciclo da pastagem de inverno apresentaram peso médio de aproximadamente $290 \mathrm{~kg}$, o que é $45 \mathrm{~kg}$ inferior aos pesos médios obtidos no tratamento $30 \mathrm{~cm}(335 \mathrm{~kg})$. Esses resultados demonstram grande vantagem aos produtores, que não necessitariam destinar áreas de verão para terminação desses animais e, conseqüentemente, reduzir a área destinada à agricultura, pois o acabamento se daria em um único ciclo de pastagem de inverno.

Neste trabalho, as cargas animais responsáveis pela manutenção dos gradientes de alturas da pastagem foram de $1.708,1.215,661 \mathrm{e} 333 \mathrm{~kg} \mathrm{de} \mathrm{PV} / \mathrm{ha} /$ dia para as alturas reais de manejo de 14, 24, 39 e $47 \mathrm{~cm}$. Estes valores são superiores aos observados por Cassol (2003), em estudo realizado na mesma área, porém, com metade da dose de adubação em cobertura utilizada neste estudo (90 kg de N/ha). Esses valores encontrados confirmam as observações de outros autores de que a adubação nitrogenada em gramíneas normalmente aumenta a carga animal suportada pela pastagem (Heringer \& Moojen, 2002; Gomide, 1994).

Entretanto, altas cargas por área estão associadas à degradação da pastagem (Almeida et al., 2000) e, conseqüentemente, à imagem de sustentabilidade duvidosa. Nesse sentido, Mott (1973) afirma que a pressão de pastejo ótima deve ser considerada como a faixa na qual haja conciliação entre o ganho por animal e o ganho por área.

Os teores de PB apresentaram pequena oscilação entre os tratamentos (140 a $150 \mathrm{~g} / \mathrm{kg}$ de MS) e foi melhor descrita por regressão quadrática (Figura 4). Os valores médios de PB foram inferiores aos $164 \mathrm{~g} / \mathrm{kg}$ de MS obtidos por Lupatini et al. (1998), no nível de $150 \mathrm{~kg} /$ ha de $\mathrm{N}$, com a mesma mistura de aveia e azevém. Pilau et al. (2005) relataram valores de PB entre $130 \mathrm{e} 200 \mathrm{~g} / \mathrm{kg}$ de MS para pastagens de aveia e azevém, de acordo com o período de pastejo com novilhas de corte em recria. Portanto, segundo o valor estabelecido no NRC (1984) para a recria de novilhos de corte (129 $\mathrm{g} / \mathrm{kg}$ de MS), o teor de PB das pastagens de aveia e azevém permite expressar, para esta categoria, o máximo ganho de peso.

A DIVMO apresentou acréscimo até a altura de $30 \mathrm{~cm}$, decrescendo na maior altura de pastejo. Este efeito foi melhor descrito por uma regressão quadrática (Figura 4). Tendência semelhante em resposta a níveis de oferta de forragem foi observada por Silva et al. (1994), em experimento com capim-elefante, no qual verificaram maiores valores de DIVMO para média OF. Veiga (1983), no entanto, não observou variações na DIVMO (média geral de $718 \mathrm{~g} / \mathrm{kg}$ de MS) para resíduos de MS de folhas de 250, 1.400 e $2.500 \mathrm{~kg} / \mathrm{ha}$. Segundo Canto et al. (1997), pastagens compostas por aveia + azevém + ervilhaca apresentaram 

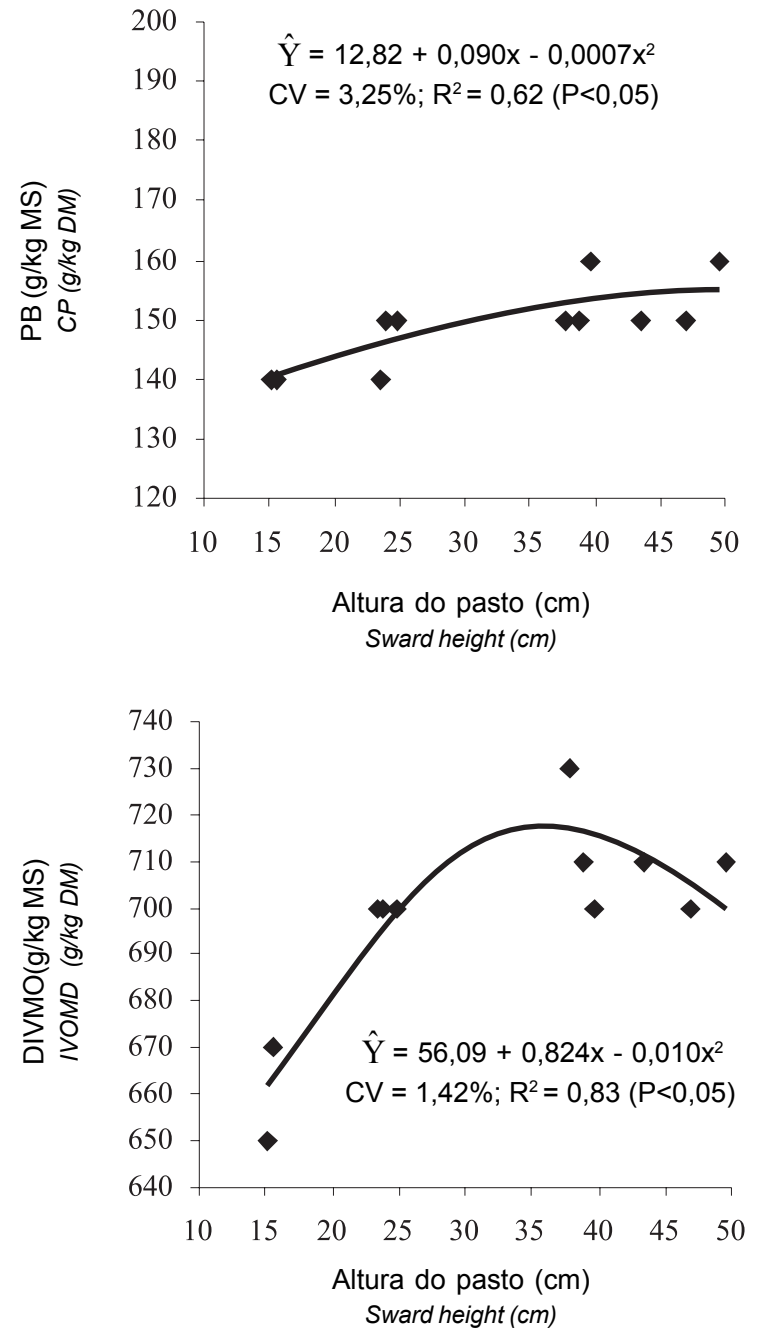

Figura 4 - Teor de PB da planta e digestibilidade in vitro da matéria orgânica (DIVMO), em g/kg de MS, de uma pastagem de aveia + azevém manejada em diferentes alturas. Fazenda Espinilho, São Miguel das Missões, 2003.

Figure 4 - Content of $C P$ and in vitro organic matter digestibility (IVOMD), in $\mathrm{g} / \mathrm{kg}$ of DM, of oat plus ryegrass pasture managed with different heights. Espinilho Farm, São Miguel of Missões, 2003.

valor de DIVMO, na média do período de pastejo, de $640 \mathrm{~g} / \mathrm{kg}$ de MS, semelhante ao observado por Frizzo et al. (2003) e Pilau et al. (2005), $650 \mathrm{~g} / \mathrm{kg}$ de MS, em experimento com novilhas em pastejo contínuo sobre pastagens de aveia e azevém.

O peso vivo dos animais antes do abate (Figura $5 \mathrm{a}$ ) elevou com o aumento da altura da pastagem $(\mathrm{P}<0,05)$, reduzindo apenas no tratamento $40 \mathrm{~cm}$, como resultado da queda da qualidade da pastagem com o avanço dos estádios de desenvolvimento das plantas (Restle et al., 1998). A resposta quadrática pode ser explicada pelos valores de GMD obtidos, ou seja, à medida que aumentou a altura da pastagem até $30 \mathrm{~cm}$ (valor estimado para máximo GMD), houve incremento no GMD, que resultou em maior peso ao abate dos animais.

O rendimento de carcaça não diferiu $(\mathrm{P}>0,05)$ entre os tratamentos, obtendo-se valores de 51,3;50,2; 51 e 51,6\% para as alturas da pastagem de 10,20,30 e $40 \mathrm{~cm}$, respectivamente, apesar da diferença significativa $(\mathrm{P}<0,05)$ no peso da carcaça quente. Esses dados indicam que, com o aumento da altura da pastagem até $30 \mathrm{~cm}$, podem ser obtidos melhores pesos de carcaça quente, favorecendo o peso dos cortes comerciais, que se expressou apenas no peso de costela (Figura 5d), visto que as variáveis peso de dianteiro e peso de traseiro não foram influenciadas pelas alturas da pastagem $(\mathrm{P}>0,05)$. No entanto, Dinius et al. (1976) observaram $60,6 \%$ de rendimento para novilhos Angus e 60,3\% para os Santa Gertrudes, valores superiores à média deste estudo (51\%). Restle et al. (1994) reportaram dados semelhantes em estudo no qual todos os valores ficaram em torno de $52 \%$ de rendimento. Pequenas diferenças no rendimento de carcaça com o incremento do peso de abate (Figura 5a) também foram citadas por Dinkel et al. (1969), de 59,4; 59; 61,4 e 61,5\%, em animais Hereford abatidos com 363, 408, 454 e $499 \mathrm{~kg}$, respectivamente. Moody et al. (1970) também observaram aumento no rendimento de carcaças de animais abatidos com 361, 388, 416 e $437 \mathrm{~kg}$, com rendimentos de 58, 59, 60 e 60\%, na mesma ordem. O maior rendimento de carcaça nos animais com peso mais elevado é, em parte, conseqüência de um grau de acabamento mais adiantado, com maior deposição de gordura na carcaça (Restle et al., 1997), observado nas carcaças do tratamento $30 \mathrm{~cm}$ (Tabela 1).

O peso de carcaça fria (Figura 5c) apresentou mesma tendência que o de carcaça quente (Figura $5 b$ ), como esperado. Todavia, destaca-se a redução de peso após o período de resfriamento das carcaças, que ficou em torno de $2 \%$ nos tratamentos 20,30 e $40 \mathrm{~cm}$, enquanto, no tratamento $10 \mathrm{~cm}$, foi de $4 \%$, indicando maiores perdas de peso na carcaça após o abate no tratamento de menor oferta de forragem. A espessura de gordura serve como proteção contra a desidratação no resfriamento das carcaças e, portanto, foi responsável pela quebra no rendimento das carcaças dos animais submetidos a menores alturas de pastagens. Valores de espessura de gordura semelhantes ao observado neste trabalho para pastagens manejadas a $30 \mathrm{~cm}$ de altura $(2,8 \mathrm{~mm})$ foram descritos por Lorenzoni et al. (1986), de 3,2 mm para animais Angus e por Restle et al. (1994), de 3,0 mm para todos os animais, independentemente da idade de castração.

Observa-se na Figura 5 aumento das diferentes variáveis físicas das carcaças com o aumento da altura da pastagem até o momento em que a qualidade da pastagem decresceu facilmente na altura de $40 \mathrm{~cm}$, por meio da DIVMO (Figura 4). 
Abaid (1981) verificou redução no corte traseiro (49,5 vs 48,8\%), aumento no corte costilhar (13,3 vs $14,0 \%$ ) e similaridade no corte dianteiro (37,2 vs $37,3 \%$ ) quando as carcaças passaram de leves para pesadas. O mesmo foi observado neste estudo, no qual os valores de corte traseiro (51,4 vs $48,9 \%)$, de costilhar (12,3 vs $14,0 \%$ ) e dianteiro ( 38,2 vs $37,1 \%$ ) apresentaram comportamento similar à medida que as carcaças passaram de leves para pesadas. De acordo com Galvão (1991), o menor rendimento de carcaças em animais mais leves foi ocasionado pelo menor grau de acabamento (menos deposição de gordura na carcaça) e pelo maior peso relativo de couro, pés e cabeça.

Quanto ao escore de condição corporal e ao grau de acabamento (Tabela 1), os tratamentos influenciaram apenas o ECC $(\mathrm{P}<0,05)$, que apresentou resposta quadrática. ECC e GA demonstraram tendência muito similar à evolução do GMD observado neste trabalho, comprovando a importância de se priorizar o desempenho individual quando se busca qualidade de carcaça, fundamental tanto para o produtor como para o frigorífico. Quanto às características de gordura de cobertura (GA) e à tipificação (CONF) das carcaças (Tabela 1), os animais criados exclusivamente em

(a)

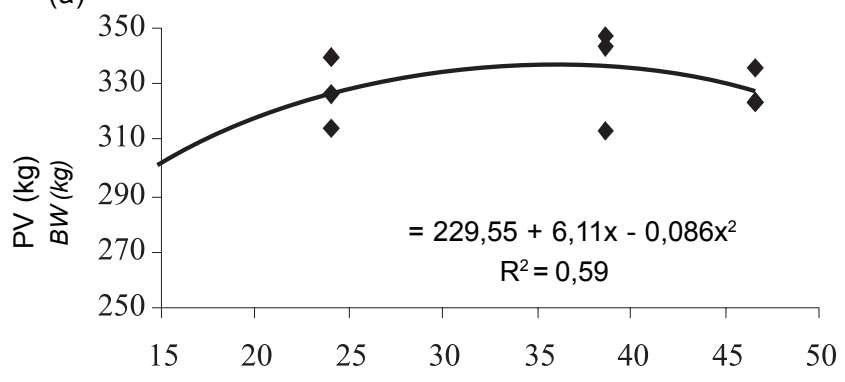

Altura do pasto $(\mathrm{cm})$ Sward height $(\mathrm{cm})$
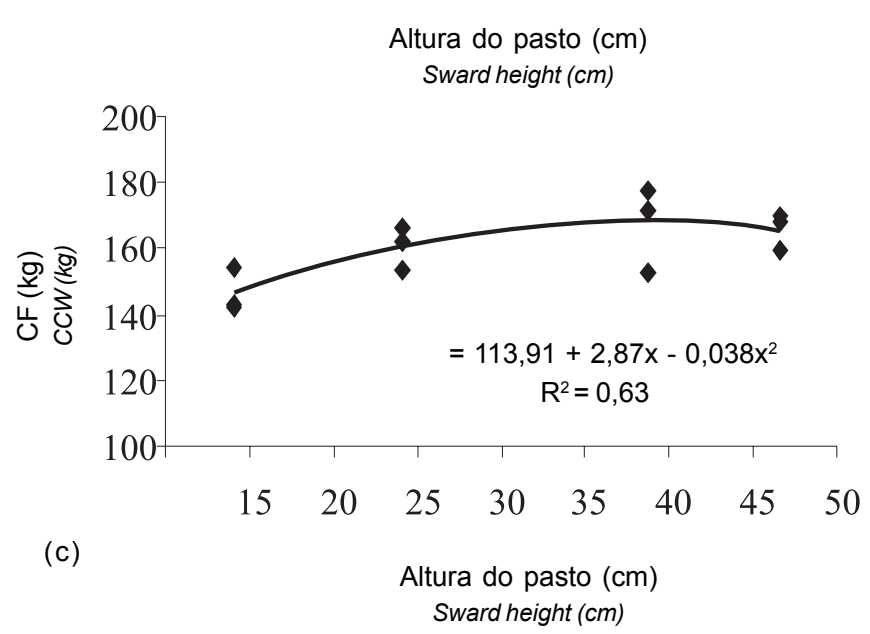

pastagem cultivada de aveia + azevém são deficientes nestes aspectos, apresentando carcaças com conformação retilínea e não atingindo o mínimo exigido pelo frigorífico $(3,0 \mathrm{~mm}), \mathrm{o}$ que não é empecilho para o abate desse tipo de animal, haja vista suas inúmeras vantagens em maciez de carne, proporcionadas pela idade. Ressalta-se que o frigorífico classificou essas carcaças como de "novilho superprecoce", satisfazendo às próprias exigências de peso e conformação. Caso necessário, esta situação pode ser melhorada com a suplementação a campo, com concentrado na fase final do período de terminação (Restle et al., 1999).

Os dados obtidos neste experimento e em outros desenvolvidos no Sul do Brasil demonstram o alto potencial de produção de carne bovina em pastagens. Deve-se considerar que as elevadas produções por área geradas no tratamento de $10 \mathrm{~cm}$ de altura da pastagem $(540 \mathrm{~kg}$ de $\mathrm{PV} / \mathrm{ha}$ em 109 dias) aumentam as possibilidades de degradação e de mudanças nas características físicas do solo e, quando da utilização de animais em áreas destinadas à agricultura, é importante salientar que esse tratamento proporcionou a menor massa de forragem e a menor quantidade de resíduo remanescente sobre a superfície do solo, reduzindo,

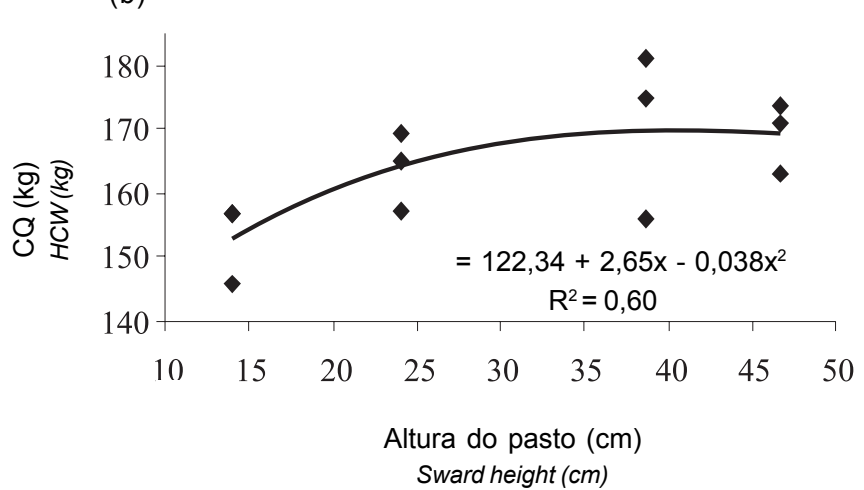

Figura 5 - Peso vivo ao abate (PV) (a), peso carcaça quente (CQ) (b), peso carcaça fria (CF) (c) e peso costela (PC) (d) de novilhos mantidos em pastagem de aveia + azevém manejada sob diferentes alturas e abatidos aos 14 meses de idade. Fazenda Espinilho, São Miguel das Missões, 2003.

Figure 5 - Body weight (BW) (a), hot carcass weight (HCW) (b), cold carcass weight (CCW) (c) and rib weight (RW) (d) of 14 months age-beef steers grazing oat plus ryegrass pasture managed with different heights. Espinilho Farm, São Miguel of Missões, 2003. 
Tabela 1 - Escore de condição corporal ao abate (ECC), grau de acabamento (GA) e conformação (CONF) de carcaças de novilhos de 14 meses de idade terminados em pastagem de aveia e azevém manejada em diferentes alturas. Fazenda Espinilho, São Miguel das Missões, 2003

Table 1 - Body condition score (BCS), fat thickness (FT) and carcass finishing (FIN) of young steers grazing oat plus ryegrass pasture managed with different heights. Espinilho Farm, São Miguel of Missões, 2003

\begin{tabular}{lccc}
\hline $\begin{array}{l}\text { Tratamento } \\
\text { Treatment }\end{array}$ & $\begin{array}{c}\text { ECC } \\
B C S\end{array}$ & $\begin{array}{c}\text { GA } \\
\text { TF }\end{array}$ & $\begin{array}{c}\text { CONF } \\
F I N\end{array}$ \\
\hline 10 & 3,1 & 2,25 & \\
Retilínea & & & \\
20 & 3,4 & 2,33 & Retilínea \\
30 & 3,6 & 2,77 & Retilínea \\
40 & 3,5 & 2,33 & Retilínea \\
$\begin{array}{l}\text { Equação de regressão } \\
\text { Regression equation }\end{array}$ & $(1)$ & - & - \\
Coeficiente de variação & $5,4 \%$ & - & - \\
$\begin{array}{l}\text { Coefficient of variation } \\
\text { Coeficiente de determinação }\end{array}$ & $64,1 \%$ & - & - \\
Coefficient of determination & & & \\
\hline
\end{tabular}

$1 \hat{\mathrm{Y}}=2,218+0,08 \mathrm{x}-0,001 \mathrm{x}^{2}$

portanto, a quantidade de palhada quando em plantio direto subseqüente. Por isso, em um sistema de integração lavoura-pecuária, é preciso encontrar $\mathrm{CA}$ ou altura da pastagem que permita ótimo desempenho individual e máxima produção por área sem prejudicar a lavoura de grãos.

Outra alternativa para o abate de novilhos aos 14 meses em sistemas de pastejo seria a consorciação dessas gramíneas com leguminosas e/ou a suplementação energética visando acelerar a velocidade de ganho de peso e a deposição de gordura dos animais e oportunizar a obtenção de carcaças de melhor qualidade.

\section{Conclusões}

O desempenho individual de novilhos de corte em pastagens de aveia + azevém é otimizado com o aumento da altura de manejo até valores próximos a $40 \mathrm{~cm}$.

O ganho por área e a carga animal diminuem linearmente com o aumento da altura da pastagem, indicando uma faixa de valor ótimo de manejo da pastagem em torno de $25 \mathrm{~cm}$ de altura.

Melhores resultados em características quantitativas da carcaça são obtidos quando a pastagem de aveia + azevém é manejada com altura de 25 a $35 \mathrm{~cm}$. Portanto, pastagens hibernais integradas em sistemas com cultivo de grãos permitem, em um único ciclo, a terminação de novilhos aos 14 meses, resultando em produto de alta qualidade.

\section{Agradecimento}

Ao Grupo de Pesquisa em Ecologia do Pastejo da UFRGS, aos Departamentos de Plantas Forrageiras e Agrometeorologia e de Solos da Faculdade de Agronomia/ UFRGS, à Agropecuária Cerro Coroado e à CAPES.

\section{Literatura Citada}

ABAID, F.R.C. Aspectos quantitativos e qualitativos de carcaças de novilhos abatidos em diferentes idades e grupos de peso. Santa Maria: Universidade Federal de Santa Maria, 1981. 74p. Dissertação (Mestrado em Zootecnia) - Universidade Federal de Santa Maria, 1981.

ALEXANDER, R.H. The establishment of a loboratory procedure for the "in vitro" determination of digestibility. Auchincruive: West of Scotland Agricultural College, 1969. 27p (Research Bulletin, 42).

ALLDEN, W.G.; WHITTAKER, I.A.D. The determinants of herbage intake by grazing sheep; the interrelationships of factors influencing herbage intake and availability. Australian Journal of Agriculture Research, v.21, n.5, p.755-766. 1970.

ALMEIDA, E.X.; MARASCHIN, G.E.; HARTHMANN, O.E.L. et al. Oferta de forragem de capim elefante anão "Mott" e a dinâmica da pastagem. Revista Brasileira de Zootecnia, v.29, n.5, p.1281-1287, 2000 .

ANUALPEC. Anuário estatístico da pecuária brasileira. São Paulo: Argos Comunicação, 2004. 400p.

ASSMANN, A.L.; PELISSARI, A.; MORAES, A. et al. Produção de gado de corte e acúmulo de matéria seca em sistema de integração lavoura-pecuária em presença ou ausência de trevo branco e nitrogênio. Revista Brasileira de Zootecnia, v.33, n. 1, p.37-44, 2004.

BARTHRAM, G.T. Sward structure and the depth the grazed horizon. Grass and Forage Science, v.36, n.2, p.130-131, 1981.

BARTHRAM, G.T. Experimental techniques: the HFRO sward stick. Aberdeen: Hill Farming Research Organization/Biennial Report, 1985. p.29-30.

CANTO, M.W.; RESTLE, J.; QUADROS, F.L.F. et al. Produção animal em pastagens de aveia (Avena strigosa Schreb.) adubada com nitrogênio ou em mistura com ervilhaca (Vicia sativa L.) Revista Brasileira de Zootecnia, v.26, n.2, p.396-402, 1997.

CARNEVALLI, R.A.; Da SILVA, S.C.; CARVALHO, C.A.B. et al. Desempenho de ovinos e respostas de pastagens de Coastcross submetidas a regimes de desfolha sob lotação contínua. Pesquisa Agropecuária Brasileira, v.36, n.6, p.919-927, 2001 a.

CARNEVALLI, R.A.; Da SILVA, S.C.; FAGUNDES, F.L. et al. Desempenho de ovinos e respostas de pastagens de Tifton 85 (Cynodon spp.) sob lotação contínua. Scientia Agrícola, v.58, n. 1, p.7-15, 2001b.

CARNEVALLI, R.A.; Da SILVA, S.C. Desempenho de ovinos e respostas de pastagens de Florakirk (Cynodon spp.) submetidos a regimes de desfolha sob lotação contínua. Boletim da Indústria Animal, v.57, n.1, p.53-63, 2000.

CARVALHO, P.C.F.; RIBEIRO FILHO, H.M.N.; POLI, C.H.E.C. et al. Importância da estrutura da pastagem na ingestão e seleção de dietas de animais pelo animal em pastejo. In: MATTOS, W.R.S. et al. (Eds.) Produção animal na visão dos brasileiros. Piracicaba: Fundação de Estudos Agrários Luiz de Queiroz, 2001. p. $853-871$.

CARVALHO, P.C.F.; PRACHE, S.; DAMASCENO, J.C. O processo de pastejo: desafios da procura e apreensão da forragem pelo herbívoro. In: REUNIÃO ANUAL DA SOCIEDADE BRASILEIRA DE ZOOTECNIA, 36., 1999, Porto Alegre. Anais... Porto Alegre: Sociedade Brasileira de Zootecnia, 1999. v.2, p. 253-268. 
CASSOL, L.C. Relações solo-planta-animal num sistema de integração lavoura-pecuária em semeadura direta com calcário na superfície. Porto Alegre: Universidade Federal do Rio Grande do Sul, 2003.143p. Tese (Doutorado em Agronomia - Ciência do Solo) - Universidade Federal do Rio Grande do Sul, 2003.

DINIUS, D.A.; BROKKEN, R.F.; BOVARD, K.P. et al. Feed intake and carcass composition of Angus and Santa Gertrudis steers fed diets of varying energy concentration. Journal of Animal Science, v.42. n.5, p.1089-97, 1976.

DINKEL, C.A.; BRUSH, D.A.; SCHAFER, D.A. et al. Changes in the composition of beef carcasses with increasing animal weight. Journal of Animal Science, v.28, n.3, p.316-323, 1969.

EMPRESA BRASILEIRA DE PESQUISA AGROPECUÁRIA EMBRAPA. Centro Nacional de Pesquisa de Solos. Sistema brasileiro de classificação de solos. Brasília: EMBRAPA. Rio de Janeiro, 1999. 412p.

FRIZZO, A.; ROCHA, M.G.; RESTLE, J. et al. Suplementação energética na recria de bezerras de corte mantidas em pastagem de inverno. Revista Brasileira de Zootecnia, v.32, n.3, p.643$652,2003$.

GALVÃO, J.G.C. Estudo da eficiência nutritiva, características e composição física da carcaça de bovinos de três grupos raciais, abatidos em três estágios de maturidade. Viçosa, MG: Universidade Federal de Viçosa, 1991. 82p. Dissertação (Mestrado em Zootecnia) - Universidade Federal de Viçosa, 1991.

GOMIDE, J.A. Manejo de pastagens para produção de leite. In: SIMPÓSIO INTERNACIONAL DE FORRAGICULTURA, 1994, Maringá. Anais... Maringá: EDUEM, 1994. p.141-168p.

HERINGER, I.; MOOJEN, E.L. Potencial produtivo, alterações de estrutura e qualidade da pastagem de milheto submetida a diferentes níveis de nitrogênio. Revista Brasileira de Zootecnia, v.31, n.2, p.875-882, 2002.

HODGSON, J. Grazing management: science into pratice. New York: Longman Scientific and Technial, 1990. 203p.

HODGSON, J.; JAMIESON, W.S. Variations in herbage mass and digestibility, and the grazing behaviour and herbage intake of adult cattle and weaned calves. Grass and Forage Science, v.36, n.1, p.39-48,1981.

LACA, E.A.; LEMAIRE, G. Measuring sward structure. In: t' MANNETJE, L.; JONES, R.M. (Eds.). Field and laboratory methods for grassland and animal production research. Wallingford: CABI Publication, 2000. p.103-121.

LEMAIRE, G.; CHAPMAN, D. Tissue flows in grazed plant communities. In: HODGSON, J.; ILliUS, A.W. (Eds.). The ecology and management of grazing. Walling ford: $C A B$ International, 1996. p.3-36.

LORENZONI, W.R.; CAMPOS, J.; GARCIA, J.A. et al. Ganho de peso, eficiência alimentar e qualidade de carcaça de novilhos búfalos, Nelores, Holandeses e mestiços Holandês x zebu. Revista Brasileira de Zootecnia, v.15, n.6, p.428-497, 1986.

LUPATINI, G.C.; RESTLE. J.; CERETTA, M. et al. Avaliação da mistura de aveia preta (Avena strigosa) e azevém (Lolium multiflorum) sob pastejo submetida a níveis de nitrogênio. Pesquisa Agropecuária Brasileira, v.33, n.11, p.1939-1943, 1998.

LUSTOSA, S.B.C. Efeito do pastejo nas propriedades químicas do solo e no rendimento de soja e milho em rotação com pastagem consorciada de inverno no sistema plantio direto. Curitiba: Universidade Federal do Paraná, 1998. 84p. Dissertação (Mestrado em Agronomia) - Universidade Federal do Paraná, 1998.

MOODY, W.G.; LITTLE, J.E.; CUNDIFF, L.V. et al. Influence of feeding a hight roughage ration on quantitative and qualitative characteristics of beef. Journal of Animal Science, v.31, n.5, p. 866-889, 1970 .

MOOJEN, E.L.; MARASCHIN, G.E. Potencial produtivo de uma pastagem nativa do Rio Grande do Sul submetida níveis de oferta de forragem revista. Ciência Rural, v.32, n.1, p.127-132, 2002.

MORAES, A. Produtividade animal e dinâmica de uma pastagem de pangola (Digitaria decumbens stent), azevém (Lolium multiflorum Lam.) e trevo branco (Trifolium repens
L.) submetida a diferentes pressões de pastejo. Porto Alegre: Universidade Federal do Rio Grande do Sul, 1991. 200p. Tese (Doutorado em Zootecnia) - Universidade Federal do Rio Grande do Sul, 1991.

MORAES, A.; MOOJEN, E.L.; MARASCHIN, G.E. Comparação de métodos de taxas de crescimento em uma pastagem submetida a diferentes pressões de pastejo. In: REUNIÃO ANUAL DA SOCIEDADE BRASILEIRA DE ZOOTECNIA, 27., 1990, Campinas. Anais... Campinas: Sociedade Brasileira de Zootecnia, 1990. p.332.

MOTT, G.O.; LUCAS H.L. The design, conduct, and interpretation of grazing trials on cultivated and improved pastures. In: INTERNATIONAL GRASSLAND CONGRESS, 6., 1952, Pensylvania. Proceedings... Pensylvania, 1952. p.1380-1385.

MOTT, G.O. Evaluating forage production. In: HEATH, M.E., METCALFE, D.S., BARNES, R.F. (Eds.) Forages. 3.ed. Ames: Lowa University Press, 1973. p.126-135.

NATIONAL RESEARCH COUNCIL - NRC. Nutrient requirement of beef cattle. 6.ed. Washington, D.C.: National Academy Press, 1984. 90p.

PILAU, A.; ROCHA, M.G.; RESTLE, J. et. al. Desenvolvimento de novilhas de corte recebendo ou não suplementação energética em pastagem com diferentes disponibilidades de forragem. Revista Brasileira de Zootecnia, v.34, n.5, p.1483-1492, 2005.

PONTES, L.S.; CARVALHO, P.C.F.; NABINGER, C. et. al. Fluxo de biomassa em pastagem de azevém anual (Lolium multiflorum Lam) manejada em diferentes alturas. Revista Brasileira de Zootecnia, v.33, n.3, p.529-537, 2004

QUADROS, F.L.F.; MARASCHIN, G.E. Desempenho animal em misturas de espécies forrageiras de estação fria. Pesquisa Agropecuária Brasileira, v.22, n.2, p.535-541, 1987.

RESTLE, J.; GRASSI, C.; FEIJÓ, G.L.D. Característica da carcaça de bovinos de corte inteiros ou castrados em diferentes idades. Pesquisa Agropecuária Brasileira, v.29, n.10, p.1631$1635,1994$.

RESTLE, J.; LUPATINI, G.C.; VALENTE, A.V. et al. Dinâmica de uma pastagem de aveia preta (Avena strigosa) e azevém (Lolium multiflorum) submetida a fontes de nitrogênio. In: REUNIÃO ANUAL DA SOCIEDADE BRASILEIRA DE ZOOTECNIA, 34. 1997, juiz de Fora. Anais... Viçosa, MG: Sociedade Brasileira de Zootecnia, 1997. p.179-181.

RESTLE, J.; LUPATINI, G.C.; ROSO, C. et al. Eficiência e desempenho de categorias de bovinos de corte em pastagem cultivada. Revista Brasileira de Zootecnia, v.27, n.2, p.397404, 1998.

RESTLE, J.; ROSO, C.; SOARES, A. B. Produção animal e retorno econômico em misturas de gramíneas anuais de estação fria. Revista Brasileira de Zooetcnia, v.28, n.2, p.235-243, 1999.

SARMENTO, D.O.L. Comportamento ingestivo em pastos de capim-Marandu submetidos a regimes de lotação contínua. Piracicaba: Escola Superior de Agricultura Luiz de Queiróz, 2003. 76p. Dissertação (Mestrado em Zootecnia) Escola Superior de Agricultura Luiz de Queiroz, 2003.

STATISTICAL ANALYSIS SYSTEM - SAS. SAS/STAT user's guide: statistics. 4.ed. Version 6, Cary: 1989. v.2, 943p.

SILVA, D.S.; GOMIDE, J.A.; QUEIROZ, A.C. Pressão de pastejo em pastagem de capim-elefente anão (Pennisetum purpureum, Schum. cv. Mott): 2. Efeito sobre o valor nutritivo, consumo de pasto e produção de leite. Revista Brasileira de Zootecnia, n.23, v.3, p.453-464, 1994.

TEDESCO, M.J. Extração simultânea de N, P, K, Ca e Mg em tecido de plantas por digestão com $\mathrm{H}_{2} \mathrm{O}_{2}-\mathrm{H}_{2} \mathrm{SO}_{4}$. Porto Alegre: Universidade Federal do Rio Grande do Sul, 1982. 23p. (Informativo Interno, 01-82).

VEIGA, J.B. Effect of grazing management upon a dwarf elephantgrass (Pennisetum purpureum Schum.) pasture. Gainesville: University of Florida, 1983. 197p. Thesis (Doctor of Philosophy) - University of Florida, 1983.

Recebido: 01/08/05 Aprovado: 19/04/06 